Chapman University

Chapman University Digital Commons

ESI Publications

Economic Science Institute

$5-1-2016$

\title{
An Experimental Investigation of Procurement Auctions with Asymmetric Sellers
}

John Aloysius

University of Arkansas

Cary A. Deck

ChapmanUniversity, deck@chapman.edu

Li Hao

University of Arkansas

Ryan French

Chapman University, rfrench@chapman.edu

Follow this and additional works at: http://digitalcommons.chapman.edu/esi_pubs

Part of the Economic Theory Commons, and the Other Economics Commons

\section{Recommended Citation}

Aloysius, J., Deck, C., Hao, L., \& French, R. (2016). An experimental investigation of procurement auctions with asymmetric sellers. Production and Operations Management, 25(10), 1763-1777. https://doi.org/10.1111/poms.12576

This Article is brought to you for free and open access by the Economic Science Institute at Chapman University Digital Commons. It has been accepted for inclusion in ESI Publications by an authorized administrator of Chapman University Digital Commons. For more information, please contactlaughtin@chapman.edu. 


\section{An Experimental Investigation of Procurement Auctions with Asymmetric Sellers}

\section{Comments}

This is the accepted version of the following article:

Aloysius, J., Deck, C., Hao, L., \& French, R. (2016). An experimental investigation of procurement auctions with asymmetric sellers. Production and Operations Management, 25(10), 1763-1777. https://doi.org/ $10.1111 /$ poms. 12576

which has been published in final form at DOI: 10.1111/poms.12576. This article may be used for noncommercial purposes in accordance with Wiley Terms and Conditions for Self-Archiving.

\section{Copyright}

Wiley 


\section{Accepted Manuscript}

Title: An Experimental Investigation of Procurement Auctions with Asymmetric Sellers

Authors: John Aloysius, Cary Deck, Li Hao, Ryan French

DOI: $\quad$ http://dx.doi.org/doi:10.1111/poms.12576

Reference: $\quad$ POMS 12576

To appear in: Production and Operations Management

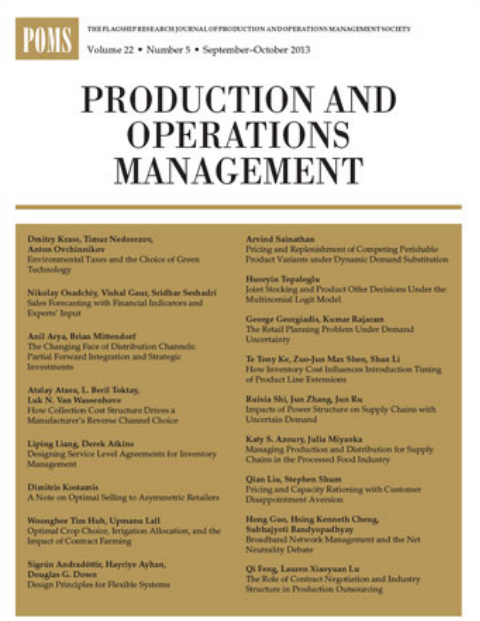

Please cite this article as: Aloysius John., et al., An Experimental Investigation of Procurement Auctions with Asymmetric Sellers. Production and Operations Management (2016), http://dx.doi.org/doi:10.1111/poms.12576

This article has been accepted for publication and undergone full peer review but has not been through the copyediting, typesetting, pagination and proofreading process, which may lead to differences between this version and the Version of Record. Please cite this article as doi: 10.1111/poms. 12576 
Article Type: Original Article

\title{
An Experimental Investigation of Procurement Auctions with Asymmetric Sellers
}

\author{
John Aloysius \\ Supply Chain Management Department, 475 Walton College of Business \\ University of Arkansas, Fayetteville, AR 72701 \\ jaloysius@walton.uark.edu \\ 479-575-3003 \\ Cary Deck \\ Economics Department, 425 Walton College of Business \\ University of Arkansas, Fayetteville, AR 72701 \\ Department of Economics at the University of Alaska Anchorage \\ Economic Science Institute, Chapman University \\ cdeck@walton.uark.edu \\ 479-575-6226 \\ Li Hao \\ Economics Department, 475d Walton College of Business \\ University of Arkansas, Fayetteville, AR 72701 \\ lhao@walton.uark.edu \\ 479-575-4499 \\ Ryan French \\ Economic Science Institute, Chapman University \\ Orange, CA 92866 \\ rfrench@chapman.edu \\ 714-628-2899
}

\begin{abstract}
Electronic reverse auctions are a commonly used procurement mechanism. Research to date has focused on suppliers who are ex ante symmetric in that their costs are drawn from a common distribution. However, in many cases a seller's range of potential costs depends on their own operations, location, or economies of scale and scope. Thus, understanding how different bidder This article has been accepted for publication and undergone full peer review but has not been through the copyediting, typesetting, pagination and proofreading process, which may lead to differences between this version and the Version of Record. Please cite this article as doi:

10.1111/poms.12576

This article is protected by copyright. All rights reserved.
\end{abstract}


types impact auction outcomes is key when designing an auction. This paper reports the results of the first controlled laboratory experiment designed to compare prices between first-price and second-price procurement auctions for homogeneous goods when seller cost types are asymmetric and the number of bidders varies. The results indicate that first-price auctions generate lower prices regardless of market composition. The results also reveal that first-price auctions are at least weakly more efficient than second-price auctions despite the theoretical prediction that the reverse should hold in asymmetric auctions. Post-hoc analysis of individual bidders' behavior in first-price auctions revealed evidence that bidders systematically underbid when their cost realizations were close to the lower bound. Furthermore, bidders adjust their behavior based on the type of the other bidders in the market in a manner inconsistent with theory. Consequently, adding a third bidder to a two-bidder market is not advantageous to the buyer unless that third bidder is a low-cost type.

Keywords: Procurement, Reverse Auction, Asymmetric Auctions, Laboratory Experiment.

History: Received: February 2014; Accepted: March 2016 by Elena Katok after three revisions.

\section{Introduction}

Electronic reverse auctions are now a ubiquitous method for procurement. ${ }^{1}$ Because they open up the process to a larger number of potential bidders and reduce the cost and effort of participation, the hope is that this will lead to more competitive bidding. It is common for firms to qualify suppliers based on product and service quality before conducting the auction (Kumar 2013). Moreover, Kostamis et al. (2009) raise the concern that the buyer's choice of auction format might depend on whether an additional supplier is qualified to bid.

There is a recent move toward attracting greater diversity of bidders by large firms such as General Electric, GlaxoSmithKline, Hewlett Packard, Dell, and Sun Microsystems with increased engagement from smaller firms as suppliers (Wyld 2011). The share of federal contracting dollars

\footnotetext{
1 The term reverse auction is used as the roles of buyers and sellers are reversed from regular forward auctions in which buyers bid for a product offered by a seller. In a reverse auction, regardless of the auction rules, sellers bid for the right to supply a product to a buyer who proffers the contract with the product specifications.
}

This article is protected by copyright. All rights reserved. 
awarded to small businesses between 2006 and 2011 ranged from 20.5\% to 22.8\% annually (Wyld 2013). ${ }^{2}$ The overall growth rate for small business awards by the federal government using reverse auctions was 181\% over the time period 2008-2012 (Wyld 2013). Technology and globalization are also enabling firms from around the world to participate in auctions. Thus, the variations in operations, economies of scope and scale, and geographic locations could lead to vastly different production costs, regulatory compliance costs, and transportation costs to the delivery point (Baldwin and Lopez-Gonzalez 2014). For these reasons, the typical academic assumption that firms have costs drawn from a common distribution even when supplying a homogeneous good may not be applicable in many real world settings.

The evidence that a greater number of bidders result in lower prices is also mixed. Mithas and Jones (2007) find some evidence that the number of bidders has no effect on buyer surplus. They call for more research on this issue, and point to the need to explore alternative explanations. In practice, however, many procurement auctions require only two or three bidders. States such as New York and North Carolina have such policies, as do many firms (Gazette of India 2005; Kulp and Randall 2005; New York University at Albany 2013; North Carolina Statutes and Codes 2013).

While there is a large academic literature examining reverse auctions (see Katok 2011), there is limited work examining the more realistic scenario where bidders come from a variety of backgrounds and thus asymmetric cost distributions. Given the complexity of allowing asymmetry, the extant theoretical work studies exactly two asymmetric bidders who are also assumed to be rational and risk-neutral (see Kaplan and Zimir 2012). Maskin and Riley (2000) consider a twobidder auction where one bidder is from a high value distribution and the second bidder is from a low value distribution. The only difference between the two types is a shift in the respective distributions: formally one bidder has a cost drawn from $[a, b]$ while the other has a cost drawn from $[a+c, b+c] .{ }^{3}$ Maskin and Riley (2000) show that the first-price auction dominates the secondprice auction under some stringent assumptions (that the distributions are convex and logconcave). Kirkegaard (2012) relaxes these strong assumptions and shows that the primary result that the first-price auction is better for the party holding the auction - holds more generally. Recent experimental work by Elmaghraby et al. (2012) introduces asymmetric sellers in a model with heterogeneous quality; however, sellers are symmetric in costs after adjusting for quality

${ }^{2}$ In the most recent fiscal year there were 24,880 awards made through Fedbid (the online marketplace of the federal government) totaling over a billion dollars to small businesses (Wyld 2013).

${ }^{3}$ This work was done in the context of a standard auction, but one can switch between the two settings in a straight forward manner (see Ausubel 2003).

This article is protected by copyright. All rights reserved. 
differences. Another recent experimental study by Saini and Suter (2013) investigates the bidding behavior of two shifted asymmetric sellers, only in first-price auctions.

However, we are unaware of any previous work that evaluates the behavioral performance across first- and second- price auction mechanisms or that considers more than two sellers when there are shift asymmetries. Hence, this study aims to fill a gap in the existing procurement auction literature with a laboratory experiment that varies three factors: (1) the market mechanism (firstprice vs. second-price auctions), (2) the number of suppliers in the market (two vs. three suppliers), and (3) the distribution of types (percentage of low-cost suppliers) participating in the auction.

\section{Related Literature}

There is a growing literature on bidding behavior in reverse auctions. Elmaghraby et al. (2012) compare rank-based feedback, full-price feedback, and no feedback to buyers in open-bid auctions. While they consider asymmetric supports for seller cost structures, our research enhances theirs in two ways: (1) In their research setting the firms with higher costs also supply goods with higher quality so that the quality adjusted distribution of costs are in fact symmetric between firms. (2) They consider dyadic auctions and do not consider the competitive effect of a third firm. In contrast to commonly held beliefs in practice that full-price feedback should result in more competition due to bid visibility, rank-only feedback resulted in lower prices than full-price feedback. While Elmaghraby et al. (2012) do not study sealed-bid auctions in the laboratory, Jap (2003) found no significant difference in buyer costs between sealed-bid and open bid reverse auctions in the field. In the current research we consider sealed-bid auctions using two market mechanisms: first-price and second-price auctions.

When the same set of suppliers bid against each other repeatedly, both revelation of the winners' bid and the revelation of all bids at the end of successive auctions has been shown to lead to higher bid prices (Kannan 2012). Greenwald et al. (2010) point out that electronic marketplaces typically feature two types of uncertainties: cost-structure uncertainty, which is uncertainty about supplier costs, and market structure uncertainty, that geographically distributed suppliers face about the number of competitors. In buyer-determined auctions sellers supply higher quality leading to higher market efficiencies, and buyers who can consider reputation effects prefer buyerdetermined auctions over price-based auctions (Brosig-Koch and Heinrich 2014). In our sealed-bid studies sellers are anonymous in a stranger design so that there are no reputational effects.

This article is protected by copyright. All rights reserved. 
There are a few experimental studies that investigate behavior in asymmetric auctions. In their theoretical work, Maskin and Riley (2000) make a distinction between a shift, where both ends of a common support are shifted by a constant amount for one of the two bidders and a stretch, where only one end of the support is shifted. Güth, Ivanova-Stenzel, and Wolfstetter (2005) compare standard two-bidder first-price and second-price auctions with a stretch asymmetry. They observe bidders being more aggressive in the first-price auction than predicted and they find prices being more favorable to the party holding the auction with a first-price auction. Saini and Suter (2013) study a procurement auction with a shift in which one seller's cost is drawn from the high distribution and the other's is drawn from the low distribution. In their one shot auctions, the theoretical predictions are generally supported although bidders are more aggressive than predicted. Our research setting differs from theirs as they do not consider the competitive effects of more than two sellers or compare auction mechanisms for two bidders. Pagnozzi and Saral (2013) also consider two asymmetric cost sellers in their experimental investigation, but their setting is a multi-object auction with resale. In addition, there is also a literature on procurement auctions in which products are differentiated on non-price attributes (Engelbrecht-Wiggans and Katok 2006; 2007; Fugger et al. 2015; Haruvy and Katok 2013; Shachat and Swarthout 2010) All of these studies feature bidders with symmetric costs (i.e., seller costs are drawn from a common distribution).

\section{Experimental Design and Procedures}

To explore behavior in shift asymmetry procurement auctions, we conduct an incentivized experiment in a controlled laboratory setting. In each experimental auction, a computerized buyer solicits offers for a fictitious item. Seller output is assumed to be homogeneous so that the buyer only cares about the price and not the identity of the supplier. Subject sellers observe their own induced cost for providing the item, as well as the number of other sellers and the distribution from which those suppliers' induced costs were drawn.

In the experiment there are two types of sellers: low-cost types and high-cost types. Low-cost types have induced costs that are distributed Uniform $\left[c_{L}=0, \bar{c}_{L}=20\right]$ while high-cost types have induced costs that are distributed Uniform $\left[c_{H}=10, \bar{c}_{H}=30\right]$. Note that a "high-cost" type may actually have a lower cost than a "low-cost type" in any given realization.

This article is protected by copyright. All rights reserved. 
The experiment varies three factors:

Factor 1: The allocation mechanism is either a first-price or second-price sealed-bid auction. Subject sellers earn a profit from winning the auction and receiving a price greater than their own cost. The lowest offer always wins (with ties broken randomly), while the price received by the winner depends on the auction mechanism. In a first-price sealed-bid auction the price equals the lowest bid and in a second-price sealed-bid auction the price equals the second lowest bid.

Factor 2: The number of bidders in the auction is either two or three.

Factor 3: The percentage of bidders who are low-cost types ranges from $0 \%$ to $100 \%$, and depends on the number of bidders.

The auction mechanism is varied between-subject, so each subject only participates in first-price, or second-price auctions, but not both. The number of bidders and bidder type compositions are varied within-subject where each subject experiences various market compositions competing against one or two other bidders. In each session, a group of 8 subjects, each at a private computer station, read auction format specific instructions. Subjects then answered a series of comprehension questions and participated in three practice auction periods, which were followed by 36 paid auction periods. Copies of the directions and the comprehension questions are provided in the Appendix. Subjects do not know how many total periods there will be in the study, but do know that they will be paid their cumulative earnings in cash at the end of the session. All costs and prices in the experiment are denoted in terms of Experimental Dollars (valued at the pre-specified rate of $5 \mathrm{E} \$=1 \mathrm{US} \$$ ).

In each auction period, the 8 subjects are randomly and anonymously assigned to different markets of two or three sellers. The subjects learn their type and realized cost for the period as well as the number and types of the other sellers in the auction. Let $\mathrm{H}$ denote a high-cost type seller and let $\mathrm{L}$ denote a low-cost type seller. There are seven possible market compositions involving two or three sellers: LL, LH, HH, LLL, LLH, LHH, and HHH. ${ }^{4}$ A session involves 16 repetitions of each of the 7 market compositions. The periods in which the different combinations of market compositions occur are randomized over the course of the session. After each auction, subjects receive feedback regarding the price in their auction and their own profit. To reduce variation between sessions and

${ }^{4}$ Given the homogeneity of the supplied items HL is isomorphic to LH. HLH and HHL are isomorphic to LHH, and HLL and LHL are isomorphic to LLH. For consistency, we always list the low-cost types first when referring to a market composition.

This article is protected by copyright. All rights reserved. 
auction mechanisms, one set of groupings, types, and cost realizations is drawn and used in all 12 sessions.

Subjects were recruited from a database of over 3000 study volunteers at the behavioral laboratory of a large state university. A total of 96 subjects participated in the experiment. Half of these were assigned to first-price sealed-bid markets and the other half were assigned to secondprice sealed-bid markets. While some of the subjects had participated in other studies, none had participated in any related auction experiments. In addition to their salient earnings, subjects received an initial endowment of $\$ 10$, including the lab's standard participation payment. The average total payment for the 60-minute experiment was $\$ 19.22$.

\section{Equilibrium Bidding Strategies and Ex Ante Predictions}

In this section we outline the theoretical predictions of equilibrium bidding strategies of lowand high-cost sellers in all market types. The predictions for the symmetric markets (LL, HH, LLL, and $\mathrm{HHH}$ ) are well known for both first-price and second-price auctions, at least under the assumption of risk neutral bidders. The predictions for risk neutral bidders in a first-price asymmetric LH market can be found in Kaplan and Zamir (2012). In their derivation, Kaplan and Zamir (2012) assume that the disadvantaged bidder will bid truthfully when such a bid has no chance of winning because it is off the support of bids the advantaged bidder might place. In the procurement setting, this amounts to the high-cost type bidding its cost when its cost exceeds the bid a low-cost type with a cost of 20 would place. To identify the equilibrium for risk neutral bidders in first-price LLH and LHH markets, we maintain this assumption.

For the three bidder asymmetric first-price auctions, we start with the expected profit equations for each type of bidder in each market composition. From these equations we would like to derive the Nash-Equilibrium bidding functions for each cost type. Let $B_{L}$ and $B_{H}$ represent the bid function for the low-cost type and high-cost type respectively, which are assumed to be monotonically increasing in cost and continuous. We can then define $C_{L}(b)$ and $C_{H}(b)$ as the respective inverse bid functions with supports $\left[b_{L}, \bar{b}_{L}\right]$ and $\left[b_{H}, \bar{b}_{H}\right]$, where these intervals denote the range of bids for which someone wins the auction with positive probability as in Kaplan and Zamir (2012). It is straightforward to extend Lemma 4 of Kaplan and Zamir (2012) to the LLH and

LHH cases to show that both inverse functions share the same upper support which we define as $\bar{b}$.

This article is protected by copyright. All rights reserved. 
However, it is not necessary for both types to share the same lower support in the LLH composition as the two low-cost types may be incentivized to bid below $\underline{c}_{H}$ when competing against each other. Following Appendices A.2 and A.3 of Kaplan and Zamir (2012), the upper boundary conditions for each type are $C_{H}(\bar{b})=\bar{b}$ and $C_{L}(\bar{b})=\bar{c}_{L}=20$. From these conditions we can derive $\bar{b}$ in each case. In LLH $\bar{b}=\bar{c}_{L}=20$ and in LHH $\bar{b}=\frac{\bar{c}_{H}+2 \bar{c}_{L}}{3}=23.33$.

The expected profit for a bidder is defined as follows where $f_{c b}$ and $F_{c b}$ represent the probability density and cumulative density functions of bidder b's cost distribution, respectively.

$$
E\left[\pi_{b}\right]=\int_{\underline{\sigma} b}^{\bar{c}_{b}}\left(B_{b}(c)-c\right) f_{c b}(c) \prod_{k \neq b}\left(1-F_{c_{k}}\left(B_{k}^{-1}\left(B_{b}(c)\right)\right) d c\right.
$$

In the equation above, $B_{b}(c)-c$ is the profit margin for bidder $b$ who has cost $c$ and bids $B_{b}(c)$. The product term at the end of the equation gives the probability that the bidder wins the auction given the bidding strategy of the other players. This profit expression can be rewritten in terms of the inverse bid functions, yielding the following.

$$
E\left[\pi_{b}\right]=\int_{\underline{b} b}^{\bar{b}}\left(b-C_{b}(b)\right) f_{c b}\left(C_{b}(b)\right) \prod_{k \neq b}\left(1-F_{c_{k}}\left(C_{k}(b)\right) d b\right.
$$

Because the low-cost type may bid below $\underline{c}_{H}$ in the LLH case and thus effectively only compete against the other low-cost type, this bidder's expected profit function can intuitively be expressed in two components, where the second term captures the profits when the high-cost type is effectively out of the market.

$$
\begin{aligned}
E\left[\pi_{L}\right]=\int_{B_{H}(\underline{c} H)}^{\bar{b}}\left(b-C_{b}(b)\right) f_{c_{b}}\left(C_{b}(b)\right) \prod_{k \neq b}\left(1-F_{c_{k}}\left(C_{k}(b)\right) d b\right. \\
+\int_{\underline{b}_{L}}^{B_{H}(\underline{c} H)}\left(b-C_{L}(b)\right) f_{c_{L}}\left(C_{L}(b)\right)\left(1-F_{c_{L}}\left(C_{L}(b)\right) d b\right.
\end{aligned}
$$

Taking the first order conditions and rearranging them gives the following in the LHH case.

This article is protected by copyright. All rights reserved. 


$$
\begin{aligned}
C_{H}^{\prime}(b) & =\frac{\bar{c}_{H}-C_{H}(b)}{2\left(b-C_{L}(b)\right)} \\
C^{\prime}{ }_{L}(b) & =\frac{\left(c_{L}-C_{L}(b)\right)\left(c_{H}-C_{H}(b)+\left(C_{H}(b)-b\right) C_{H}{ }^{\prime}(b)\right)}{\left(b-C_{H}(b)\right)\left(c_{H}-C_{H}(b)\right)}
\end{aligned}
$$

For the LLH case, the first order conditions can be written as follows.

$$
\begin{aligned}
& C^{\prime}{ }_{H}(b)=\frac{\left(\bar{c}_{H}-C_{H}(b)\right)\left(c_{L}-C_{L}(b)+\left(C_{L}(b)-b\right) C_{L}{ }^{\prime}(b)\right)}{\left(b-C_{L}(b)\right)\left(c_{L}-C_{L}(b)\right)} \\
& C_{L}^{\prime}(b)=\left\{\begin{array}{cl}
\frac{\bar{c}_{L}-C_{L}(b)}{2\left(b-C_{H}(b)\right)}, & b \geq B_{H}\left(c_{H}\right) \\
\frac{\bar{c}_{L}-C_{L}(b)}{b-C_{L}(b)}, & b<B_{H}\left(c_{H}\right)
\end{array}\right.
\end{aligned}
$$

Solving either of these systems of ordinary differential equations directly is problematic because the slope of a low-cost type's bid function is undefined at $\bar{b}$. Therefore, we turn to a genetic algorithm to identify reasonable boundary conditions for $\underline{b}_{L}$ and $\underline{b}_{H}$ for deriving numerical solutions for the bid functions. The genetic algorithm can be described as an iterative agent-based simulation. Each agent (bidder) starts with a randomly generated set of strategies (bid functions) and updates these strategies over time in response to interactions with other agents. Multi-population genetic algorithms work very well in competitive environments because each agent operates independently with a distinct strategy and fitness function. The fitness function is a metric for evaluating the performance of a strategy, which for an auction is the expected profit from using a particular bid function given the bid functions of the other two agents.

To implement the genetic algorithm, the set of allowable bid functions has to be parameterized. Given the highly non-linear nature of the known equilibrium bid functions in LH market composition, allowable bid functions for the genetic algorithm are taken to be piecewise linear. This specification allows for the bid function to be convex over some ranges and concave over others. The bid functions assign specific numeric values to a set of 41 evenly spaced cost realizations, Ć.

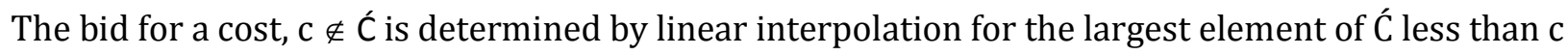
and the smallest element of ć larger than c. For example, a low-cost type is assigned a bid value for costs of $0.0,0.5,1.0, \ldots, 19.5,20.0$ and the bid function is assumed to be linear in the intervals between these costs. These bid functions were designed to obey the boundary conditions described above. We used a three-population genetic algorithm; one population for each bidder so that two

This article is protected by copyright. All rights reserved. 
bidders of the same type can evolve independently. Each population was initialized with 100 randomly generated monotonic strategies, $B_{b}^{1} O \ldots B_{b}^{100} O$.

The iterative component of the genetic algorithm starts with each agent choosing a candidate (to be the equilibrium) strategy. For the initial iteration a strategy is randomly chosen, but for all subsequent iterations the best performing strategy from the previous iteration is used. Each agent then evaluates the fitness of all strategies in their population using the candidate strategies of the other agents. The resulting fitness allows us to judge the relative performance of each strategy in the current iteration. Based on their fitnesses, the strategies within a population are replicated, replaced, or updated through a process called reproduction.

The first step in reproduction is to double the strategy set. This starts by selecting 100 parent strategies using a tournament selection process that repeatedly samples two strategies from the population, selecting the one with higher fitness. Next, the newly selected strategies are randomly paired to form 50 parent sets. From these two parents, two new strategies (children) are created by either replicating the parents (clone) or joining a portion of one parent strategy with the other parent strategy (crossover). Formally, a crossover of two parent strategies $B_{b}^{i} O$ and $B_{b}^{j} O$ is implemented by randomly choosing an element $c^{*}$ of Ć, such that the resulting children, $B_{b}^{i v} O$ and $B_{b}^{j y} 0$ are defined as follows.

$$
\begin{aligned}
& B_{b}^{i \prime}(c)= \begin{cases}B_{b}^{i}(c), & c<c^{*} \\
B_{b}^{j}(c), & c \geq c^{*}\end{cases} \\
& B_{b}^{j^{\prime}}(c)= \begin{cases}B_{b}^{j}(c), & c<c^{*} \\
B_{b}^{i}(c), & c \geq c^{*}\end{cases}
\end{aligned}
$$

After the two children strategies are created, they have a fixed probability of 0.025 of being mutated by either increasing or decreasing the given bid value at each point in ć. Thus, there is a $74 \%$ chance a bid function will experience at least one mutation. The fitnesses of the children strategies are evaluated in the same way as the original parent strategies and they are added to the population that existed at the start of the iteration. Finally, a new set of 100 strategies is created by

This article is protected by copyright. All rights reserved. 
selecting the current candidate strategy and 99 other strategies through a weighted sampling method related to the each strategy's fitness. ${ }^{5}$

There is a strong tendency for strategies with higher fitness to move on to the next iteration, but it is not guaranteed. Due to the randomness of the selection process, many of the poorly performing strategies will also carry on to the next iteration. This diversity helps to ensure that the algorithm does not get stuck in a local maxima. However, over time the number of poor performing strategies in the population will decrease and the strategies within the population will converge. To test for convergence we consider how much the candidate strategies vary from iteration to iteration.

Our genetic algorithms ran for 2500 iterations. To measure how the strategies change over time, we choose a very conservative metric that looks at the difference between the maximum and minimum value at any single point (element of ć) over a moving window of the 100 most recent iterations. This lagged greatest difference reduces to $0.65,0.62$, and 0.68 for the low-cost and two high-cost agents, respectively, in the LHH case after the first 500 iterations. In the LLH case, the lagged greatest difference reduces to $0.55,0.59$, and 0.67 for the two low-cost agents and the highcost agent respectively after the first 500 iterations. However, a more illustrative way to evaluate the convergence of the candidate strategies is presented in Figure 1. The first plot shows the candidate strategy of the low cost agent in the LHH environment for every $100^{\text {th }}$ iteration between 1 and 1000 . The second plot shows the best strategy of the same agent for every $100^{\text {th }}$ iteration between 1500 and 2500 .

${ }^{5}$ It should be noted that crossover and mutation strategies may not be monotonic. In cases where nonmonotonic bid functions were created, their fitness was assigned to be negative. Despite the resulting negative fitness, these non-monotonic bid functions still have a chance to be part the strategy set for the next iteration.

This article is protected by copyright. All rights reserved. 
Figure 1: Low cost agent candidate bid functions

Iterations 1-1000

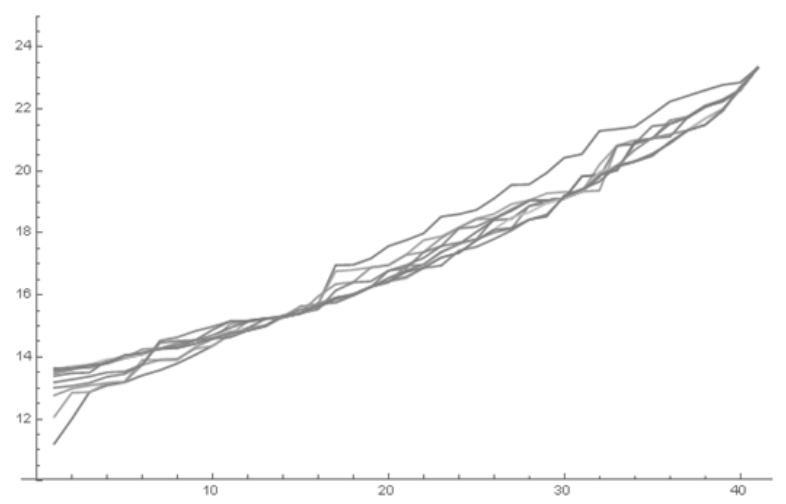

Iterations 1500-2500.

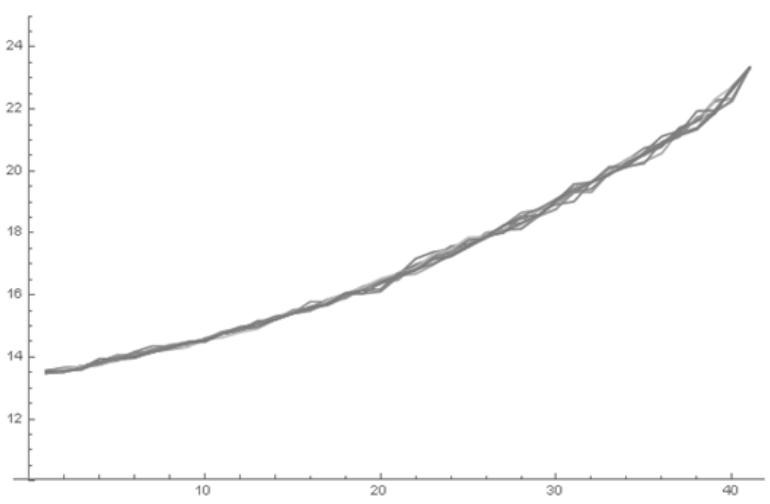

After the 2500 iterations were complete, the candidate strategies provide approximate values of the relevant $\underline{b} \mathrm{~s}$ and, in the LLH case, $B_{H}\left(c_{H}\right)$, which determines when a low cost type is effectively only competing with the other low-cost type. With these approximations, we can solve the system of ordinary differential equations using a shooting method. ${ }^{6}$

The numerical solutions for the three bidder asymmetric first-price risk neutral equilibrium bid functions are presented in Figure 2, along with the first-price risk neutral equilibrium bid functions for each of the other market compositions. Bid functions for low-cost types are shown as solid lines whereas bid functions for high-cost types are shown as dashed lines. Two interesting patterns emerge from the figure. First, conditional on the number of bidders, both types bid more as the percentage of bidders who are high-cost types increases. ${ }^{7}$ Second, while symmetric first-price auctions should be efficient, meaning that the lowest cost seller should always win the auction, asymmetric auctions are not expected to be efficient. This can be seen in the LH panel of Figure 2 as the bid function for both types are continuous and the bid function for a low-cost type lies strictly above the bid function for the high-cost type. Hence, a high-cost type with a cost realization slightly greater than the cost realization of a low-cost type would win the auction despite having a higher cost.

${ }^{6} \mathrm{~A}$ shooting method starts from a possible initial condition, a guess about $\underline{b}$ and numerically solves the system of differential equations. The guess is validated when the resulting numerical solution conforms to the known boundary condition, $\bar{b}$. Mathematica files for the genetic algorithms and numerical solutions are available upon request.

7 This relation is not strict as high-cost types in LHH and LLH both truthfully reveal their cost when their realized cost is near the top of the support.

This article is protected by copyright. All rights reserved. 
In second-price asymmetric auctions, truthful revelation remains a dominant strategy just as in symmetric markets. Hence, all bidders placing bids equal to their costs is an equilibrium for all seven market compositions that we consider. ${ }^{8}$ We choose not to present figures for second-price auctions corresponding to Figure 2 , as each would be simply a portion of the $45^{\circ}$ line.

Table 1 presents the expected price and the probability that the lowest cost seller wins the auction, which we refer to as efficiency, for each auction mechanism and each market composition. ${ }^{9}$ An important difference between symmetric and asymmetric auctions is apparent from this table. While first- and second-price auctions generate the same predicted price in symmetric auctions, this is not the case in asymmetric auctions. In particular, first price procurement auctions generate lower theoretical prices when bidders have (shift) asymmetric cost values.

Table 1: Ex Ante Predictions by Auction Type and Market Composition

\begin{tabular}{llcccc} 
& & \multicolumn{2}{c}{ Expected Price } & \multicolumn{2}{c}{ Expected Efficiency } \\
& & first-price & second-price & first-price & second-price \\
\hline \hline \multirow{2}{*}{ 2-person } & LL & 13.3 & 13.3 & $100 \%$ & $100 \%$ \\
auctions & LH & 18.5 & 20.5 & $84 \%$ & $100 \%$ \\
& HH & 23.3 & 23.3 & $100 \%$ & $100 \%$ \\
\hline \hline \multirow{3}{*}{3 -person } & LLL & 10.0 & 10.0 & $100 \%$ & $100 \%$ \\
auctions & LLH & 12.6 & 12.7 & $99 \%$ & $100 \%$ \\
& LHH & 16.1 & 17.3 & $86 \%$ & $100 \%$ \\
& HHH & 20.0 & 20.0 & $100 \%$ & $100 \%$ \\
\hline \hline
\end{tabular}

${ }^{8}$ It is worth noting that this truth telling equilibrium is not unique for asymmetric auctions. To see this consider a high-cost type in an LH market facing a low-cost type who bid truthfully. If this high-cost bidder truthfully revealed its cost if its cost was less than 20 and place a bid of $B>20$ for any cost above 20 , this would not impact the profit of the high-cost type and the low-cost type would have no incentive to deviate. Hence, this is an equilibrium. As a result, the expected prices shown in Table 1 are not unique although the efficiency calculations are.

${ }^{9}$ This differs from the standard definition of efficiency in laboratory experiments, which measures the percentage of the possible gains from trade that are realized, but for the two-bidder auctions these definitions coincide.

This article is protected by copyright. All rights reserved. 
Figure 2: Equilibrium Bid Functions for First-Price Auctions by Market Composition

2-bidder markets

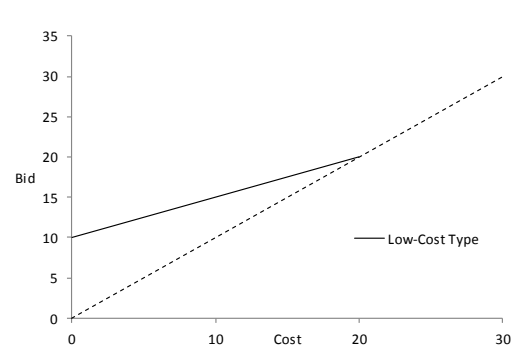

LL

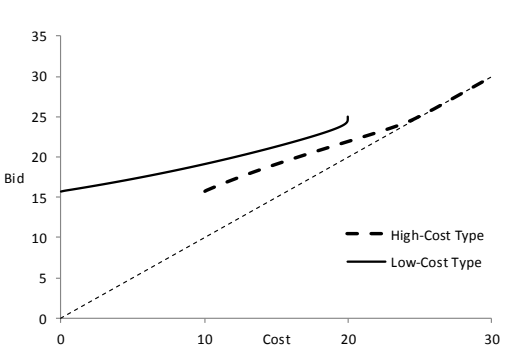

LH

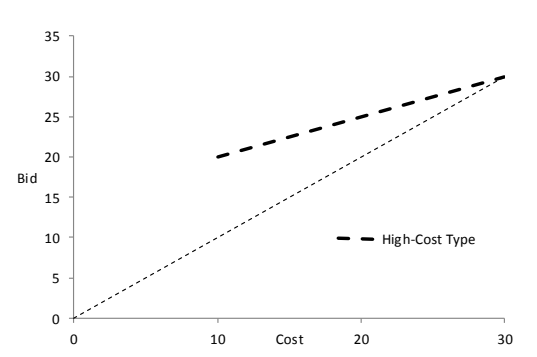

$\mathrm{HH}$

3 bidder markets

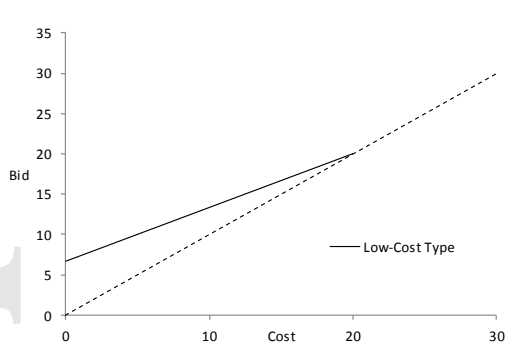

LLL

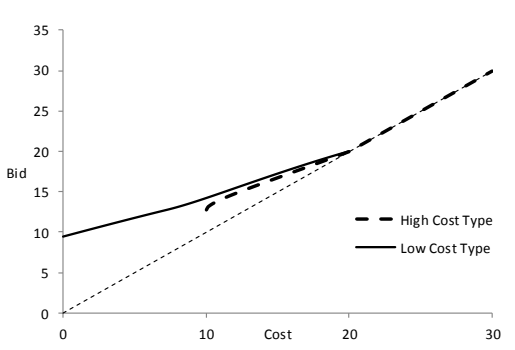

LLH

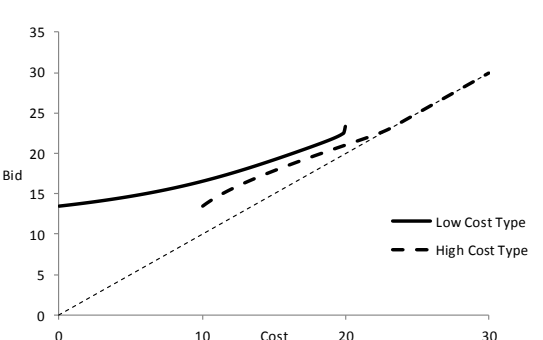

LHH

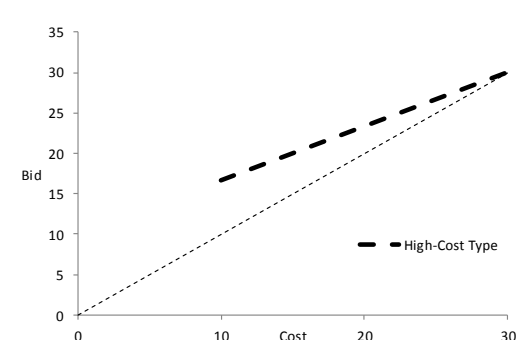

$\mathrm{HHH}$

This article is protected by copyright. All rights reserved. 


\section{Behavioral Results}

The behavioral results are organized in two subsections: market outcomes and individual bidding behaviors. First, we evaluate how price and efficiency change between auction mechanisms and across market compositions. Then, we estimate individual bidding strategies in order to shed further light on market-level results. Market outcomes are analyzed using both non-parametric tests and OLS regressions with robust standard errors clustered at the session level to account for potential serial correlation within the session. Individual bidding strategies are estimated via random effects models at the subject level, in addition to robust standard errors clustered at the session level. The data for the findings are from 1,344 laboratory auctions.

\section{Market Outcomes: Auction Price and Efficiency}

Table 2 summarizes empirical performance of each auction type, including average market price and efficiency, as well as standard deviations in parentheses.

Table 2: Summary Statistics: Observed Price and Efficiency per Auction Type

\begin{tabular}{|c|c|c|c|c|c|c|c|}
\hline & \multirow[b]{2}{*}{$\begin{array}{c}\text { Market } \\
\text { Composition }\end{array}$} & \multicolumn{3}{|c|}{ Price } & \multicolumn{3}{|c|}{ Efficiency } \\
\hline & & $\begin{array}{l}\text { First- } \\
\text { Price }\end{array}$ & $\begin{array}{l}\text { Second- } \\
\text { Price }\end{array}$ & $\begin{array}{l}\text { p-value in } \\
\text { WMW rank } \\
\text { sum test }\end{array}$ & $\begin{array}{l}\text { First- } \\
\text { Price }\end{array}$ & $\begin{array}{l}\text { Second- } \\
\text { Price }\end{array}$ & $\begin{array}{l}\text { p-value in } \\
\text { WMW rank } \\
\text { sum test }\end{array}$ \\
\hline \multirow{3}{*}{$\begin{array}{l}\text { 2-Bidder } \\
\text { Auctions }\end{array}$} & LL & $\begin{array}{c}8.14 \\
(0.675)\end{array}$ & $\begin{array}{c}10.77 \\
(0.290)\end{array}$ & $0.004^{* * *}$ & $\begin{array}{c}92.7 \% \\
(0.073)\end{array}$ & $\begin{array}{c}89.6 \% \\
(0.032)\end{array}$ & 0.309 \\
\hline & LH & $\begin{array}{c}12.96 \\
(0.951)\end{array}$ & $\begin{array}{c}20.93 \\
(0.945)\end{array}$ & $0.004^{* * *}$ & $\begin{array}{c}93.8 \% \\
(0.079)\end{array}$ & $\begin{array}{c}90.6 \% \\
(0.052)\end{array}$ & 0.314 \\
\hline & $\mathrm{HH}$ & $\begin{array}{c}21.69 \\
(0.434)\end{array}$ & $\begin{array}{c}23.83 \\
(0.902)\end{array}$ & $0.004^{* * *}$ & $\begin{array}{c}90.6 \% \\
(0.095)\end{array}$ & $\begin{array}{c}81.3 \% \\
(0.056)\end{array}$ & $0.070^{*}$ \\
\hline \multirow{4}{*}{$\begin{array}{l}\text { 3-Bidder } \\
\text { Auctions }\end{array}$} & LLL & $\begin{array}{c}8.94 \\
(0.334)\end{array}$ & $\begin{array}{c}9.78 \\
(0.608)\end{array}$ & $0.025^{* *}$ & $\begin{array}{c}89.6 \% \\
(0.065)\end{array}$ & $\begin{array}{c}69.8 \% \\
(0.139)\end{array}$ & $0.014^{* *}$ \\
\hline & LLH & $\begin{array}{c}9.59 \\
(0.740)\end{array}$ & $\begin{array}{c}12.08 \\
(0.829)\end{array}$ & $0.004^{* * *}$ & $\begin{array}{c}87.5 \% \\
(0.040)\end{array}$ & $\begin{array}{c}76.0 \% \\
(0.092)\end{array}$ & $0.039 * *$ \\
\hline & LHH & $\begin{array}{c}11.93 \\
(0.545)\end{array}$ & $\begin{array}{c}16.03 \\
(0.757)\end{array}$ & $0.004^{* * *}$ & $\begin{array}{c}89.6 \% \\
(0.032)\end{array}$ & $\begin{array}{c}83.3 \% \\
(0.123)\end{array}$ & 0.611 \\
\hline & $\mathrm{HHH}$ & $\begin{array}{c}18.32 \\
(0.495)\end{array}$ & $\begin{array}{c}22.07 \\
(0.827)\end{array}$ & $0.004^{* * *}$ & $\begin{array}{c}92.7 \% \\
(0.073)\end{array}$ & $\begin{array}{c}86.5 \% \\
(0.083)\end{array}$ & 0.180 \\
\hline
\end{tabular}

This article is protected by copyright. All rights reserved. 
Notes: In parentheses are standard deviations.

The nonparametric WMW (Wilcoxon-Mann-Whitney) rank sum test is based on a comparison of the 6 session-averages from first-price auctions and 6 session-averages from second-price auctions, for each market composition. All tests are two-sided.

*** indicates significance at $1 \%$ level, ${ }^{* *}$ at $5 \%$, and ${ }^{*}$ at $10 \%$.

Theoretical derivations for auctions, such as the predictions in Table 1 , are by their nature ex ante; in contrast, observed prices and efficiencies are necessarily ex post in relation to cost realizations. That is, the prices and efficiencies observed in the laboratory are a function of the realized costs. Our design choice of using the same cost realizations for both first-price and secondprice auctions allows direct comparisons between the two auction mechanisms. ${ }^{10}$ The nonparametric WMW (Wilcoxon-Mann-Whitney) rank sum tests reported in Table 2 make such comparisons. The results reveal that first-price auctions systemically lead to (statistically) lower prices and (at least nominally) greater allocative efficiency than second-price auctions. These findings are generally consistent with previous experimental investigations of symmetric auctions (see e.g., Davis and Holt 1993 and Kagel and Roth 1995). The statistical results in Table 2 provide the basis for our first two findings.

Finding 1 (price comparison between mechanisms): First-price auctions generate significantly lower procurement prices than second-price auctions.

Finding 2 (efficiency comparison between mechanisms): Second-price auctions are not significantly more efficient than first-price auctions and are significantly less efficient for some market compositions (specifically $H H, L L L$, and $L L H$ ).

On the other hand, due to variations in realized costs, it is difficult to draw clear inferences from direct comparisons between market compositions, as observed differences could be due to either behavioral responses to the composition or the cost realizations. Similarly, comparisons between ex ante predicted outcomes and behavioral outcomes do not offer clear results, as the latter is conditional on cost realizations while the former is not. Hence it is not appropriate to directly compare among rows in Table 2 or to compare between entries in Tables 1 and 2. Instead, to

${ }^{10} \mathrm{An}$ inevitable feature is that our results and implications are conditional on the set of realized costs.

This article is protected by copyright. All rights reserved. 
compare observed and predicted outcomes, as well as to make comparisons across market compositions, we first calculated the conditional predicted price and efficiency for each market in the experiment. The conditional predicted price and efficiency are calculated as the price and efficiency that would be attained in the market if each bidder bid according to the theoretical prediction conditional on the realized cost.

Table 3 examines the deviation of observed market outcomes from conditional predicted outcomes in different market types. Take Model (1) for example, we run an OLS regression using observed market price minus conditional predicted price as the dependent variable, and include 14 separate indicator variables for each of the 14 combinations of market composition and auction mechanism. Standard errors are clustered at the session level to take into account correlation within a session. Constant terms are suppressed so that the coefficient is the direct measure of the deviation of the particular market type. Hence, if the observed prices match the theoretical predictions in a particular situation, then the associated coefficient would equal 0 . We conduct an identical regression for market efficiency in Model (2).

Table 3: Comparison of Conditional Predicted and Observed Market Outcomes

Model:

Dependent

Variable:
(1)

Observed Price Conditional Predicted Price
(2)

Observed Efficiency Conditional Predicted Efficiency

\begin{tabular}{|c|c|c|c|c|}
\hline & First-Price & Second-Price & First-Price & Second-Price \\
\hline \multirow[t]{2}{*}{ LL } & $-4.520 * * *$ & $-0.419 * * *$ & $-0.073 * *$ & $-0.104 * * *$ \\
\hline & $(0.264)$ & $(0.113)$ & $(0.029)$ & $(0.013)$ \\
\hline \multirow[t]{2}{*}{ LH } & $-5.820 * * *$ & -0.637 & $0.062^{*}$ & $-0.094 * * *$ \\
\hline & $(0.372)$ & (0.369) & (0.031) & $(0.020)$ \\
\hline \multirow[t]{2}{*}{$\mathrm{HH}$} & $-2.874 * * *$ & -0.049 & $-0.094 * *$ & $-0.188 * * *$ \\
\hline & $(0.170)$ & $(0.353)$ & $(0.037)$ & $(0.022)$ \\
\hline \multirow[t]{2}{*}{ LLL } & $-2.434 * * *$ & -0.342 & $-0.104 * * *$ & $-0.302 * * *$ \\
\hline & $(0.130)$ & $(0.238)$ & $(0.025)$ & $(0.054)$ \\
\hline \multirow[t]{2}{*}{ LLH } & $-3.191 * * *$ & $-0.731 * *$ & $-0.125^{* * *}$ & $-0.240 * * *$ \\
\hline & $(0.290)$ & $(0.324)$ & $(0.015)$ & $(0.036)$ \\
\hline \multirow[t]{2}{*}{ LHH } & $-3.010 * * *$ & $-1.163 * * *$ & $-0.042 * * *$ & $-0.167 * * *$ \\
\hline & $(0.213)$ & $(0.296)$ & $(0.013)$ & $(0.048)$ \\
\hline \multirow[t]{2}{*}{$\mathrm{HHH}$} & $-2.556 * * *$ & 0.443 & $-0.073 * *$ & $-0.135 * * *$ \\
\hline & $(0.194)$ & $(0.323)$ & $(0.029)$ & $(0.032)$ \\
\hline Observations & \multicolumn{2}{|c|}{1344} & \multicolumn{2}{|c|}{1344} \\
\hline $\mathrm{R}^{2}$ & \multicolumn{2}{|c|}{0.503} & \multicolumn{2}{|c|}{0.153} \\
\hline Clusters & \multicolumn{2}{|c|}{12} & \multicolumn{2}{|c|}{12} \\
\hline
\end{tabular}

This article is protected by copyright. All rights reserved. 
Notes: In both (1) and (2), market-level data are regressed with standard errors clustered at the session level. Moreover, constant terms are suppressed; hence each coefficient is the direct measure of the observed market price (efficiency) deviation from conditional predicted market price (efficiency).

OLS regressions with clustering.

${ }^{* * *}$ indicates significance at $1 \%$ level, ${ }^{* *}$ at $5 \%$, and ${ }^{*}$ at $10 \%$.

The results in Table 3 clearly show that prices are significantly below the conditional prediction for every market composition in first-price auctions. Further, these price shortfalls are economically large. For second-price auctions, prices are significantly lower than predicted for some, but not all, market compositions, but in no case is the reduction economically large. This is formalized in finding 3.

Finding 3 (comparison of observed and predicted prices): First-price auctions uniformly lead to economically and statistically lower prices than predicted while second-price auctions generate statistically lower than expected prices only in LL, LLH, and LHH markets, and the difference is never economically large.

The results in Table 3 also reveal that second-price auctions are less efficient than predicted, although because efficiency is predicted to be $100 \%$ all errors are one sided. ${ }^{11}$ Generally, first-price auctions are also less efficient than predicted; however, in the asymmetric LH market, observed efficiency is marginally higher than what is predicted. This provides the basis for Finding 4 .

Finding 4 (comparison of observed and predicted efficiency): Second-price auctions are uniformly less efficient than predicted. The allocative success of first-price auctions depends on the market composition.

The coefficients in Table 3 can also be used to compare first-price and second-price auctions, an alternative approach to the support offered above for Findings 1 and 2. Additionally, this approach can be used to compare the differences between market compositions. For example, in a first-price auction the ex ante expected difference between an LH and an LL market is 18.5-13.3 = 5.2, according to Table 1. From Tables 1 and 3, the observed difference was (18.5 - 5.8) - (13.3 - 4.5) or $5.2-(5.8-4.5)=5.2-1.3=3.9$. Thus, the difference in coefficients in Table 3 indicates the amount by which the observed outcome difference differs from the conditional predicted differences, a diffin-diff estimate. For example, in the case of moving from an LH to an LL market, the observed price

11 The same conclusion holds if a probit model is used to account for the binary nature of the efficiency measure.

This article is protected by copyright. All rights reserved. 
difference is 1.3 smaller than conditional predicted price difference. Table 4 reports the $p$-values for t-tests testing that the difference in coefficients in the first- and second-price auctions of the same market composition in Table 3 is 0 , or alternatively that the observed difference equals the predicted difference conditional on the realized costs. Table 5 reports the p-values for similar ttests based on coefficients in Table 3 comparing market compositions for a given auction format. We restrict attention to comparisons that either change the cost type of one bidder, or involve the addition of the third bidder.

Table 4. p-values for Comparisons of Observed and Predicted Differences between Auction Formats (First-Price v Second-Price)

\begin{tabular}{lccccccc} 
& \multicolumn{3}{c}{ 2-Bidder Auctions } & \multicolumn{4}{c}{ 3-Bidder Auctions } \\
Comparison & LL & LH & HH & LLL & LLH & LHH & HHH \\
\hline \hline Price & $<0.001$ & $<0.001$ & $<0.001$ & $<0.001$ & $<0.001$ & $<0.001$ & $<0.001$ \\
Efficiency & 0.339 & 0.001 & 0.052 & 0.007 & 0.014 & 0.029 & 0.177 \\
\hline \hline
\end{tabular}

Table 5. p-values for Comparison of Observed and Predicted Differences between Market Compositions

\begin{tabular}{llcccc} 
& & \multicolumn{2}{c}{ Prices } & \multicolumn{2}{c}{ Efficiency } \\
& & First-Price & Second-Price & First-Price & Second-Price \\
\hline \hline \multirow{2}{*}{ Change } & LL v LH & 0.006 & 0.602 & $<0.001$ & 0.755 \\
in Type & LH v HH & $<0.001$ & 0.192 & $<0.001$ & 0.018 \\
of a & LLL v LLH & 0.028 & 0.425 & 0.427 & 0.348 \\
Bidder & LLH v LHH & 0.643 & 0.398 & 0.002 & 0.111 \\
& LHH v HHH & 0.129 & $<0.001$ & 0.319 & 0.417 \\
\hline \hline \multirow{3}{*}{ Addition } & LL v LLL & $<0.001$ & 0.689 & 0.509 & 0.004 \\
of a & LL v LLH & 0.015 & 0.307 & 0.176 & 0.005 \\
Bidder & LH v LLH & $<0.001$ & 0.788 & $<0.001$ & 0.004 \\
& LH v LHH & $<0.001$ & 0.364 & 0.016 & 0.269 \\
& HH v LHH & 0.633 & 0.009 & 0.242 & 0.636 \\
& HH v HHH & 0.198 & 0.319 & 0.546 & 0.176 \\
\hline
\end{tabular}

The statistical tests in Table 4 provide further support for Findings 1 and 2. The significant values for efficiency differences between auction mechanisms for the LH and LHH market compositions (see the second row of Table 4) are due to the fact that in both cases second-price auctions are predicted to be substantially more efficient than first-price auctions, but in fact are

This article is protected by copyright. All rights reserved. 
observed to be statistically similar (see right-hand column of Table 2) and hence the observed difference between auction mechanisms is smaller than the predicted difference.

The statistical results in Table 5 reveal several interesting patterns. For second-price auctions, the effect of changing a bidder's type or of adding an additional bidder generally has the expected effect on price. The LLH market has the largest deviation of observed price from conditional predicted price among all second-price auctions (see Table 3). Because prices are similar to the predicted level for $\mathrm{HH}$ markets, the reduction in price from adding a low-cost type and creating an LHH market is more dramatic than predicted. Similarly, the price increases going from LHH to HHH is greater than expected.

For first-price auctions, a different story emerges from Table 5. Because bidders are relatively more aggressive in both the LL and LH markets, resulting in prices substantially below the predicted level (see Table 3) as compared to other market compositions, the impact of adding a third bidder is significantly smaller than predicted. In fact, while adding a high-cost type to an LH market is expected to lower price by $16.1-18.5=-2.4$, it actually leads to a nominal increase in the expected price of $(16.1-3.0)-(18.5-5.8)=0.4$. The results also show that the effect of changing from an LL to an LH market are not as large as predicted while the change from an LH to an HH market is greater than predicted. Similarly changing from an LLL to an LLH market does not increase prices by as much as expected. Together these two patterns show that merely adding a third bidder is not as important as attracting a low-cost type. These patterns are summarized in Finding 5.

Finding 5 (impact on expected price of changes in market composition): Changes in market composition generally have the predicted effect on expected prices in second-price auctions. In firstprice auctions however,

i. $\quad$ The price reduction from adding a third bidder is smaller than expected, and

ii. The effect of replacing a low-cost type with a high-cost type is smaller than expected as long as there remains a low-cost type in the auction, but is bigger than expected if no low-cost types remain.

With respect to efficiency, Table 5 shows that because first-price auctions in the LH market composition are more efficient than predicted, the difference in efficiency between LH markets and other markets is not as large as predicted. Otherwise, changes in composition generally have the predicted effect on efficiency except that the observed reduction in efficiency in moving from LLH to LHH is not as dramatic as predicted. For second-price auctions, LLL and LLH markets are the

This article is protected by copyright. All rights reserved. 
least efficient market compositions and LH is the most efficient. Table 5 indicates that these performances differ significantly from those of other compositions. This is summarized in Finding 6.

Finding 6 (impact on efficiency of changes in market composition): Changes in market composition typically affect efficiency in first-price auctions by the degree expected or less. In secondprice auctions where market composition is not expected to affect efficiency, it does.

Individual Behavior: Bidding Strategy

We now turn to analyzing the determinants of individual bidding strategies. To facilitate comparisons between mechanisms and across market compositions, we look at the difference between the predicted and the observed bid as a function of cost. Figures 3 and 4 provide scatter plots along with the fitted quadratic error functions and 95\% confidence intervals for bidding in first- and second-price auctions, respectively. We use a quadratic specification due to the non-linear equilibrium bid functions for asymmetric first-price auctions. For each bidder type in each market type, we estimate the following regression model allowing for a random effect for each bidder and using robust standard errors clustered at the session level.

$$
\text { observed bid - conditional predicted bid }=\alpha+\beta_{1} \times \operatorname{cost}+\beta_{2} \times \operatorname{cost}^{2}+\varepsilon
$$

It is important to note that the estimated equation is not the bid function, but rather it is the bid error. Therefore, if bidders act in accordance with the theoretical predictions then it should be that $\alpha=\beta_{1}=\beta_{2}=0$. Figures 3 and 4 provide the estimated regression along with the $p$-value for the $F$ tests that bidders are following the (risk neutral) conditional predicted strategy for each scenario.

For no market composition do low- or high-cost types follow the equilibrium bid function in a first-price auction. Instead, regardless of type or market composition, bidders in first-price auctions on average bid too low when their cost realization is near the lower bound of its support. This is our seventh finding. Such behavior is consistent with risk aversion and is commonly observed in symmetric auctions (see e.g., Davis and Holt 1993 and Kagel and Roth 1995). It also explains why we find that prices are below the predicted level (see Finding 3 ) for first-price auctions.

Finding 7 (bidding behavior in first-price auctions): In first-price auctions, bidders do not bid according to the conditional predictions. Instead they underbid when their cost is relatively low.

This article is protected by copyright. All rights reserved. 
In second-price auctions, we only observe equilibrium bidding in two cases: high-cost types in LHH and HHH markets. In all other market compositions, there is at least marginal evidence that people are not bidding truthfully for all cost realizations. This is formalized in our final finding.

Finding 8 (bidding behavior in second-price auctions): In second-price auctions, bidders only follow the dominant strategy to bid truthfully if they are a high-cost type facing two other bidders and at least one of the other bidders is also a high-cost type.

Figure 3 and 4 also shed light on the surprising, in light of the theoretical predictions, efficiency results of Finding 2. It is clear that there is more variance in bids in a second-price auction than in a first-price auction. This, combined with the fact that low-cost types do not seek as large of a profit margin as expected in first-price auctions, increases the relative frequency with which a seller with a higher cost realization places the lowest bid in a second-price auction.

This article is protected by copyright. All rights reserved. 
Figure 3: Difference between Observed Bids and Equilibrium Bids for First-Price Auctions Panel A: Two-Bidder Auctions
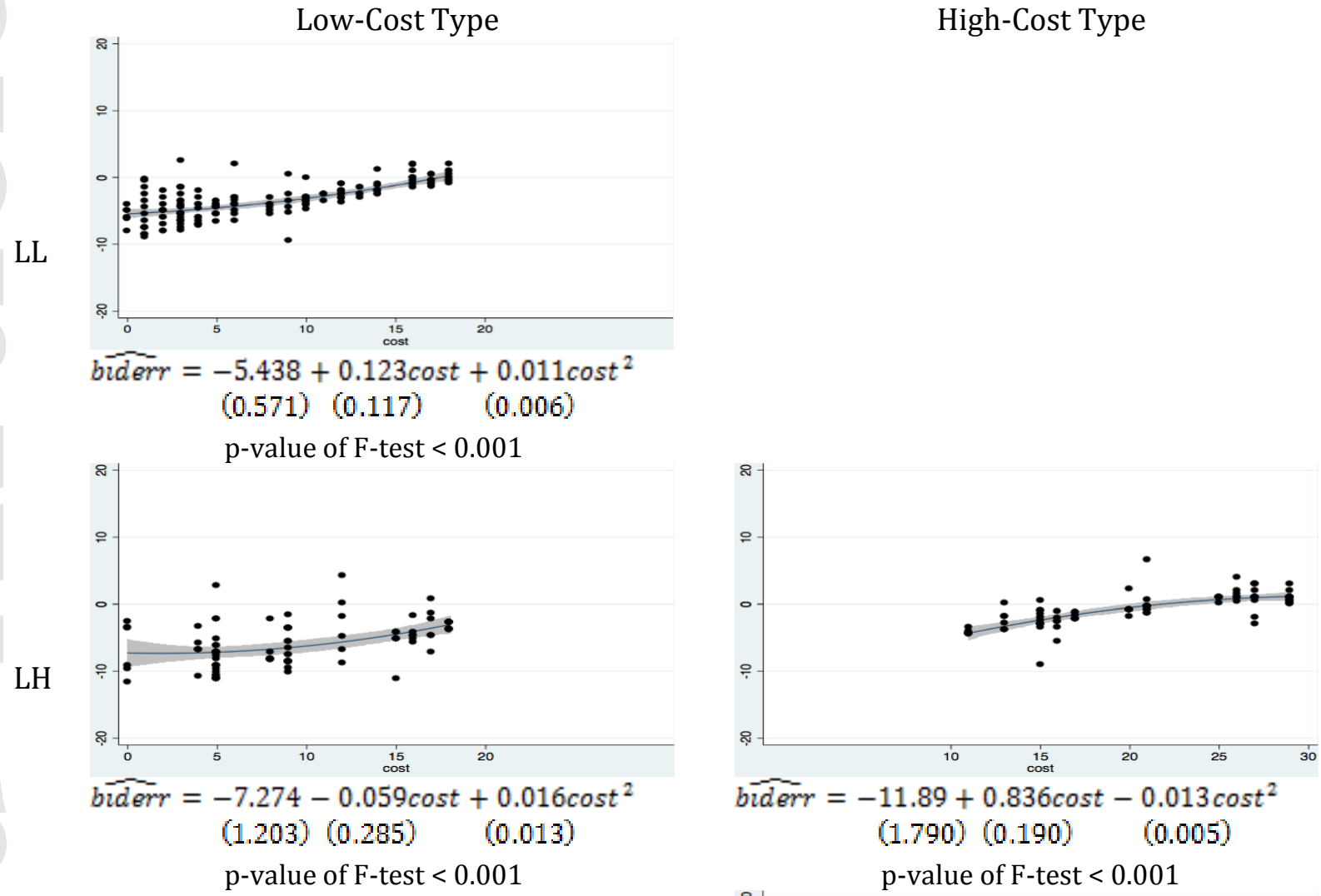

$\mathrm{HH}$

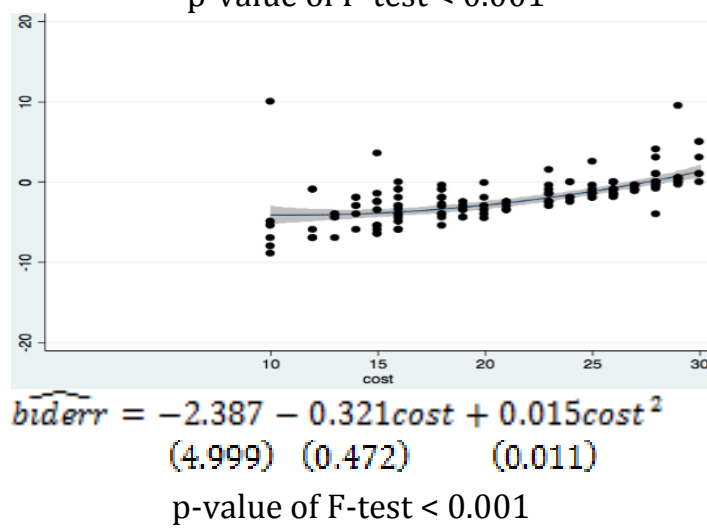

This article is protected by copyright. All rights reserved. 
Figure 3: Difference between Observed Bids and Conditional Predicted Bids for First-Price Auctions

Panel B: Three Bidder Auctions

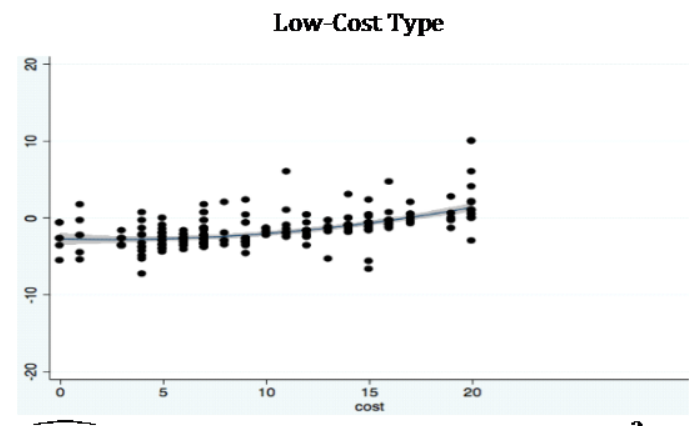

High-Cost Type

LLL.

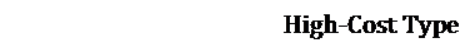

$$
\begin{aligned}
\text { bider }= & -2.712-0.068 \cos t+0.014 \cos ^{2} \\
& (0.468)(0.092) \quad(0.004)
\end{aligned}
$$
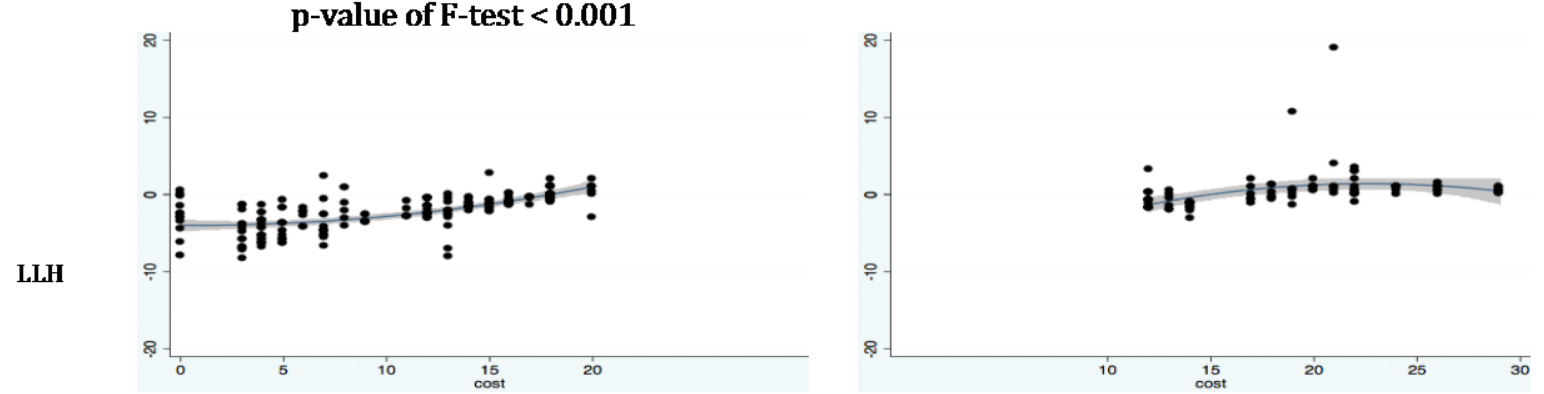

$$
\begin{aligned}
\widehat{\text { bider }}= & -3.969-0.0164 \cos t+0.013 \cos t^{2} \\
& (0.568)(0.111) \quad(0.005) \\
& \text { p-value of F-test }<0.001
\end{aligned}
$$

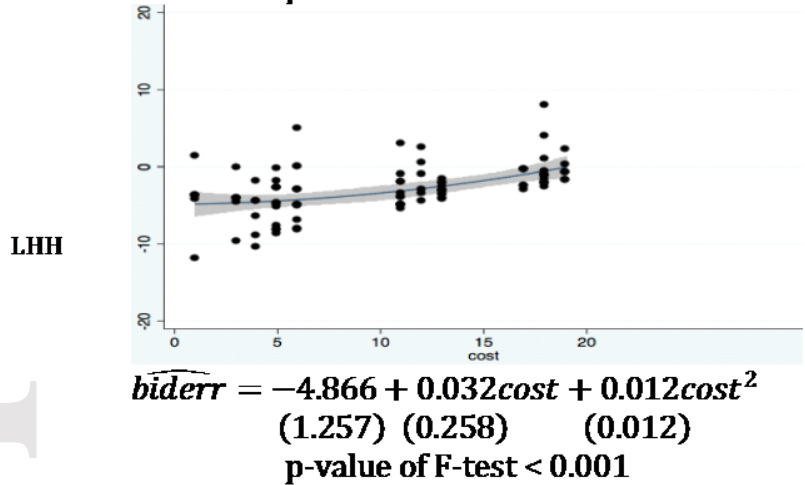

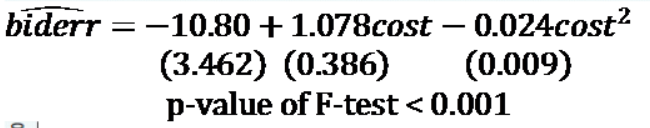

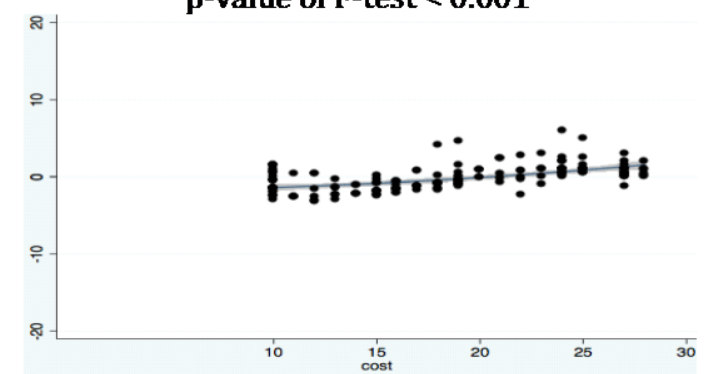

$$
\overrightarrow{b \overline{i d e r} r=}=\frac{-1.768-0.003 \cos t+0.004 \cos ^{2}}{(0.983)(0.112)}
$$

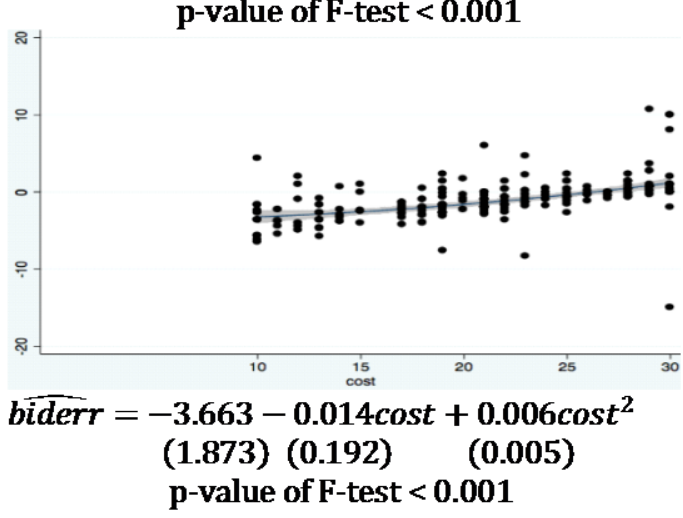

This article is protected by copyright. All rights reserved. 
Figure 4: Difference between Observed Bids and Conditional Predicted Bids for Second-Price Auctions

Panel A: Two-Bidder Auctions
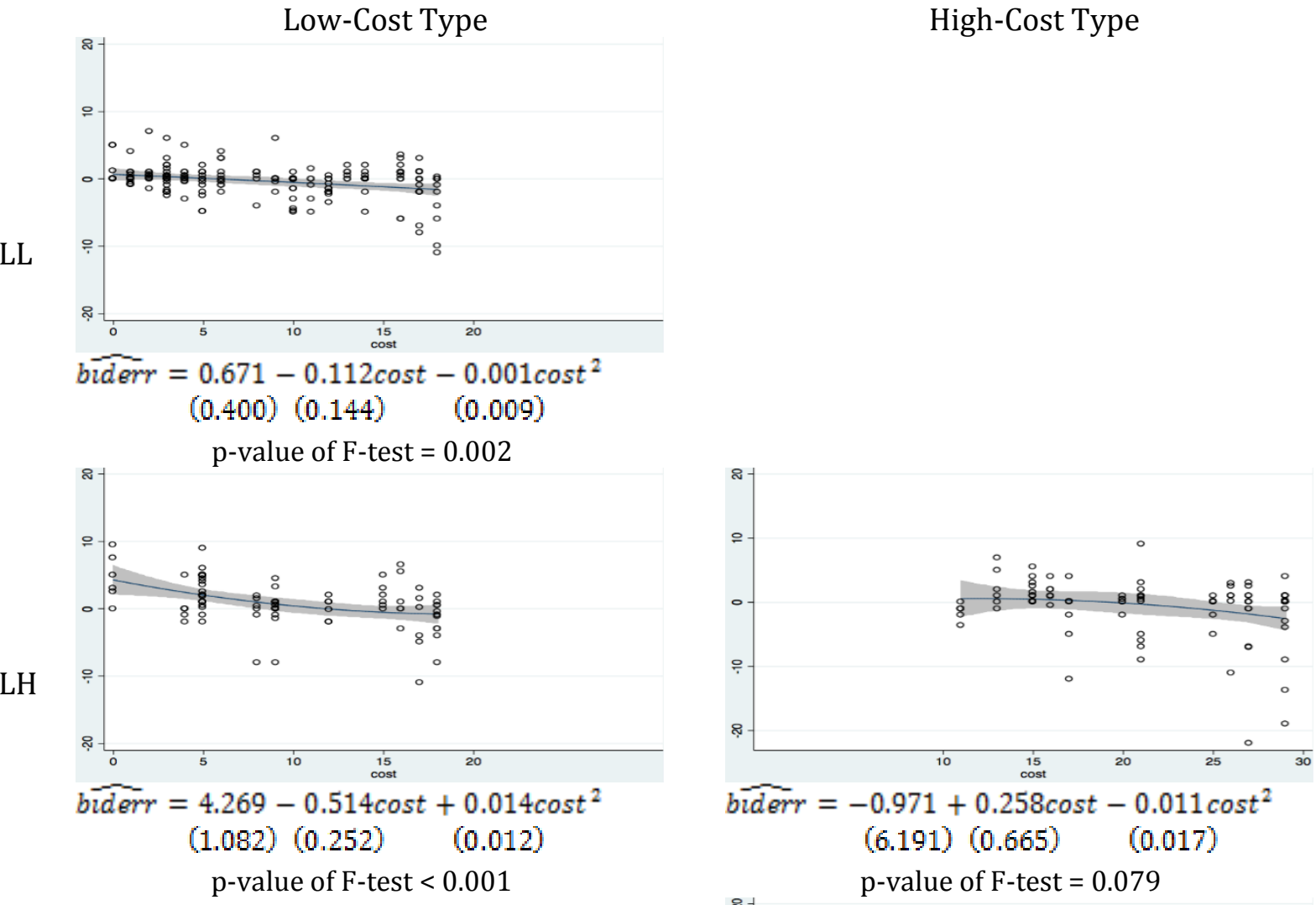

$\mathrm{HH}$

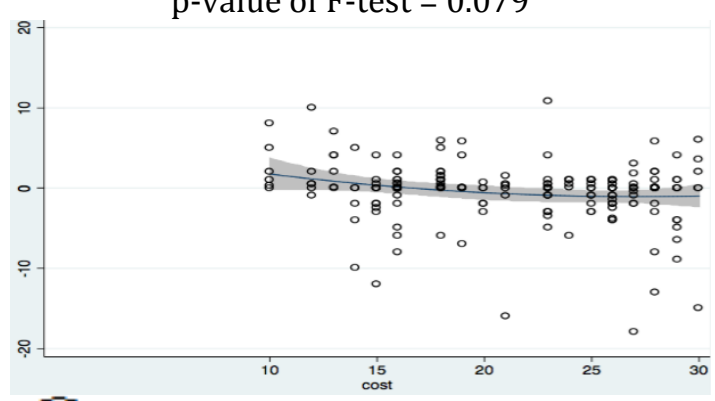

$$
\begin{aligned}
\widehat{\text { buderr }}= & 6.016-0.522 \cos t+0.010 \text { cost }^{2} \\
& (4.423)(0.425) \quad(0.010)
\end{aligned}
$$

$\mathrm{p}$-value of F-test $=0.040$

This article is protected by copyright. All rights reserved. 
Figure 4: Difference between Observed Bids and Conditional Predicted Bids for Second-Price Auctions

Panel B: Three Bidder Auctions

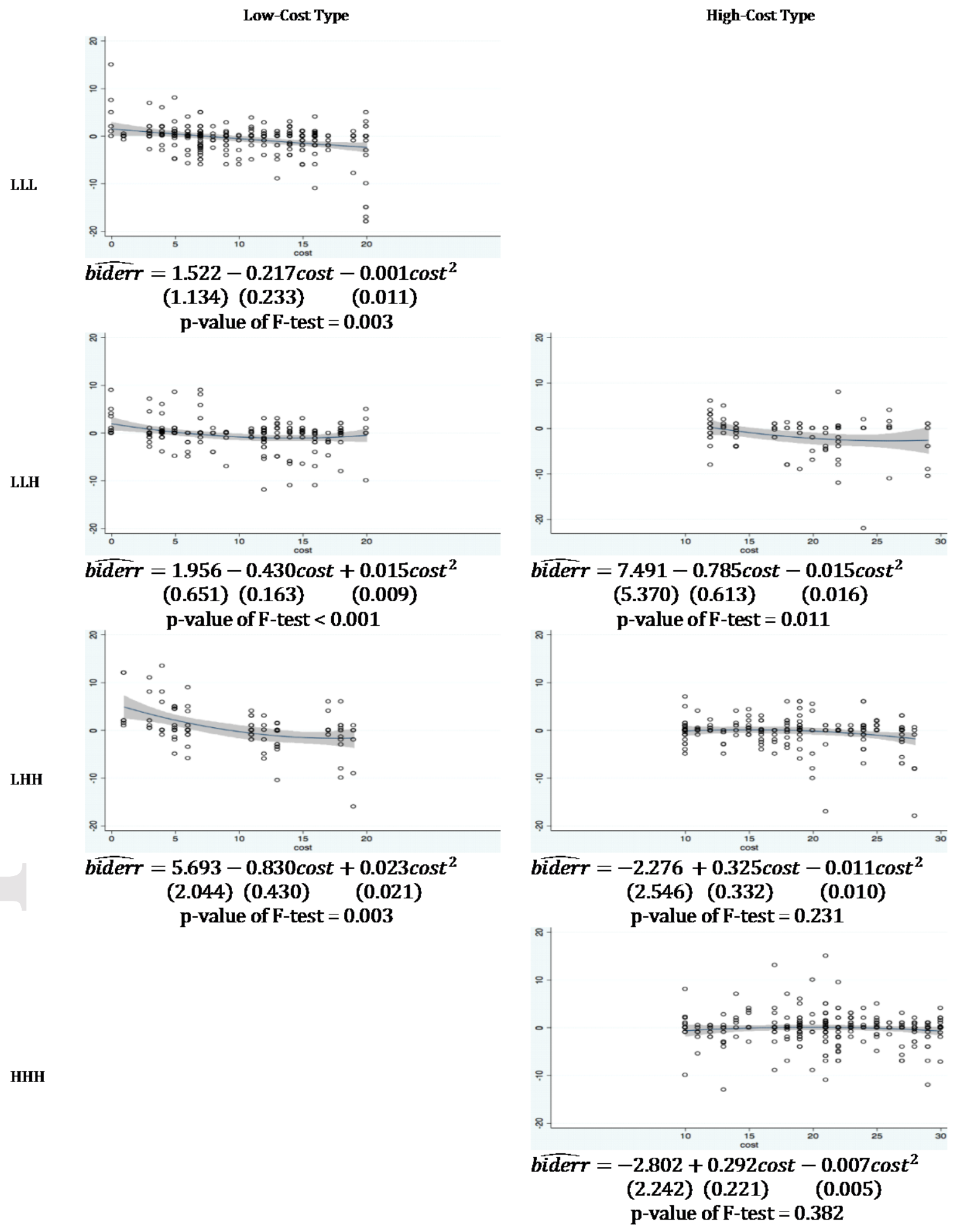

This article is protected by copyright. All rights reserved. 


\section{Concluding Remarks}

This paper reports the results of controlled laboratory experiments designed to investigate how the auction mechanism, as well as the number and type of bidders participating, impacts market outcomes and bidding behavior in asymmetric procurement auctions. In addition to two-bidder auctions where recent theoretical advances have identified analytical solutions for bidding in firstprice auctions, we study three-bidder markets as this is sometimes specified as a practical rule-ofthumb for the minimum number of bidders. In the case of three bidder markets we derive a numerical solution for the equilibrium bid functions.

At the market level, our results indicate that in the presence of (shift) asymmetries, first-price auctions lead to significantly lower procurement prices - both statistically and economically - as compared to second-price auctions. This result also demonstrates the robustness of previous experiments focusing on symmetric auctions. Whereas first- and second-price auctions are expected to be equally successful at identifying the lowest cost seller in symmetric markets, with asymmetric markets second-price auctions are expected to be strictly more efficient. However, we observe the opposite pattern in the laboratory. This reversal is due to bidders not behaving as aggressively as expected in first-price auctions and to greater variation in behavior in second-price auctions. The lack of aggressive behavior in first-price auctions also explains why we observe prices that are below the theoretical predictions for both symmetric and asymmetric market compositions with that mechanism.

We hope that this paper helps spur a reexamination of procurement auctions allowing for asymmetries. In addition to considering other auction mechanisms and more bidders in the framework used in this paper, future research should consider other asymmetries as well. The typical assumption of a uniform distribution over the support may also be overly restrictive and there is no particular reason not to allow each bidder to have their own unique distribution of costs. Once one allows for these types of changes then there is a need to explore robustness of other auction results such as the impact of feedback in open auctions or allowing for quality differentials. In the current research, bidders knew how many other bidders were in the market and their types. Another potentially interesting extension would be to consider a setting in which bidders did not know the types or number of their competitors.

A brief scan of instances of procurement auctions in practice (e.g., Gazette of India (2005), Kulp and Randall (2005), New York University at Albany (2013), North Carolina Statutes and Codes (2013), reveals that first-price auctions are a commonly used market mechanism. There are two

This article is protected by copyright. All rights reserved. 
findings on individual bidding behavior that have implications particularly salient for practitioners involved in in first-price auctions. First, we documented a behavioral regularity wherein bids were lower than the theoretical prediction when cost realizations were near the lower bound of their support (Finding 7). This finding serves to alert individuals who may bid on behalf of supplier firms to guard against a behavioral tendency toward overly competitive bidding behavior when they are likely to have a cost advantage over other supplier firms in the market. Second we found that bidders tend to change their bidding behavior in a manner inconsistent with theory in reaction to an additional bidder in the market. The price reduction from adding a third bidder is smaller than expected, and the effect of replacing a low-cost type with a high-cost type is smaller than expected as long as there remains a low-cost type in the auction, but is bigger than expected if no low-cost types remain. Consequently, adding an additional high-cost type bidder to a two-bidder market was not advantageous for the buyer, but adding a low-cost type bidder was in fact advantageous.

In conclusion we find that in procurement auctions for homogeneous goods when seller cost types are asymmetric and the number of bidders varies, first-price auctions generate lower prices regardless of market composition. First-price auctions are either equally or more efficient than second-price auctions despite the theoretical prediction that the reverse should hold in asymmetric auctions. Suppliers are warned against a tendency toward over-competitive bidding behavior in specific circumstances and buying firms are given guidance as to what types of suppliers they should seek to qualify for their procurement auctions.

\section{Acknowledgments}

The authors thank Elena Katok, an anonymous Senior Editor and four anonymous referees, as well as participants at the 2013 regional ESA and 2013 SEA conferences for their constructive suggestions. The authors also acknowledge support from the Walton College of Business at the University of Arkansas, and the Rasmussen Chair at the University of Alaska, Anchorage.

This article is protected by copyright. All rights reserved. 


\section{References}

Ausubel, L. 2003. Auction Theory for the New Economy. In D. C. Jones (ed.), New Economy Handbook, Elsevier Academic Press.

Baldwin, R., J. Lopez-Gonzalez. 2014. Supply-chain trade: A portrait of global patterns and several testable hypotheses. The World Economy, forthcoming.

Brosig-Koch, J., Heinrich, T. 2014. Reputation and mechanism choice in procurement auctions: An experiment. Production and Operations Management 23(2), 210-220.

Davis, D., Holt, C. 1993. Experimental Economics. Princeton University Press: Princeton, NJ.

Elmaghraby, W.J., Katok, E., Santamaria, N. 2012. A laboratory investigation of rank feedback in procurement auctions. Manufacturing and Service Operations Management 14 (1), 128-144.

Elmaghraby, W. 2007. Auctions within e-sourcing events. Production and Operations Management $16(4), 409-422$.

Engelbrecht-Wiggans, R., Haruvy, E., Katok, E. 2007. A comparison of buyer determined and pricebased multi-attribute mechanisms. Marketing Science 26(5) 611-628.

Engelbrecht-Wiggans, E., Katok, E. 2006. E-sourcing in procurement: theory and behavior in reverse auctions with non-competitive contracts. Management Science 52(4), 581-596.

Fischbacher, U. 2007. z-Tree: Zurich Toolbox for Ready-made Economic Experiments. Experimental Economics 10(2), 171-178.

Fugger, N., Katok, E., Wambach, A. 2015. Collusion in dynamic buyer-determined reverse auctions, Management Science, in press.

Gazette of India. 2005. Guidelines for Determination of Tariff by Bidding Process for Procurement of Power by Distribution Licensees. Downloaded from http://www.powermin.nic.in/acts_notification/electricity_act2003/pdf/CBG\%20notified\%202 7.9.07-clean.doc on 11/26/13.

Greenwald, A., Kannan, K., Krishnan, R. 2010. On evaluating information revelation policies in procurement auctions. Information Systems Research 21(1), 15-37.

This article is protected by copyright. All rights reserved. 
Güth, W., Ivanova-Stenzel, R. Wolfstetter, E. 2005. Bidding behavior in asymmetric auctions: An experimental study. European Economic Review. 49(7), 1891-1913.

Haruvy, E., Katok, E. 2013. Increasing revenue by decreasing information in procurement auctions. Production and Operations Management 22(1), 19-35.

Jap, S.D. 2003. An exploratory study of the introduction of online reverse auctions. Journal of Marketing 67, 96-107.

Kagel, J., Roth, A. 1995. The Handbook of Experimental Economics. Princeton University Press: Princeton, NJ.

Kannan, K.N. 2012. Effects of information revelation policies under cost uncertainty. Information Systems Research 23 (1), 75-92.

Kaplan, T.R., Zamir, S. 2012. Asymmetric first-price auctions with uniform distributions: Analytic solutions to the general case. Economic Theory 50(2), 269-302.

Katok, E. 2011. Buyer determined procurement auctions experiments. In The Oxford Handbook of Market Design, (Alvin Roth, Nir Vulkan, Zvika Neeman and Muriel Niederle Eds.) Oxford University Press, Oxford, UK.

Kostamis, D., Duenyas, D., Beil, D.R. 2009. Total-cost procurement auctions: impact of suppliers' cost adjustments on auctions format choice. Management Science 55 (12), 1985-1999.

Kirkegaard, R. 2012. Ranking asymmetric auctions: filling the gap between a distributional shift and stretch. Working paper. University of Guelph: Department of Economics, 1-24.

Kulp, S., Randall, T. 2005. Procurement at Betapharm Corp. (A). Harvard Business School Case Study, 2-9.

Kumar, S. 2013. Is your supply chain business operation a good fit for online reserve auctions? Transportation Journal 52 (1), 121-133.

Maskin, E., Riley, J. 2000. Equilibrium in sealed high bid auctions. Review of Economic Studies Limited (67), 439-454.

Mithas, S., Jones, J. 2007. Do auction parameters affect buyer surplus in e-auctions for procurement? Production and Operations Management 16(4), 455-470.

This article is protected by copyright. All rights reserved. 
New York University at Albany. 2013. Procurement process. Downloaded from http://www.albany.edu/purchasing/research_funded/prcedures_rf.html on 11/26/13.

North Carolina Statutes and Codes. 2013. Minimum number of bidders. Downloaded from http://www.ncga.state.nc.us/EnactedLegislation/Statutes/HTML/BySection/Chapter_143/GS_ 143-132.html on 11/26/13.

Pagnozzi, M., Saral, K. 2013. Multi-object auctions with resale: An experimental analysis. Working paper, Centre for Studies in Economics and Finance, University of Naples Federico II.

Saini, V., Suter, J. 2015. Capacity constraints and information revelation in dynamic procurement auctions: Experimental evidence. Economic Inquiry, 53(2), 1236-1258.

Shachat, J., Swarthout, J.T. 2010. Procurement auctions for differentiated goods. Decision Analysis 7 (1), 6-22.

Walmart 2013. Supplier diversity. Downloaded from http://corporate.walmart.com/suppliers/supplier-diversity/ on 11/26/13.

Wyld, D. C. 2011. Reverse auctioning: Saving money and increasing transparency. The Reverse Auction Research Center. Downloaded from http://www.reverseauctionresearch.org/ on $11 / 26 / 13$.

Wyld, D C. 2013. Doing well by doing good. IBM Center for the Business of Government. Downloaded from http://www.reverseauctionresearch.org/ on 11/26/13.

This article is protected by copyright. All rights reserved. 